The role of self-responsibility

\title{
The role of protest scenario in the neural response to the supportive
} communication

Daniel Pinazo Calatayud1*, Alfonso Barros-Loscertales2, Rosana Peris1, Noelia Ventura-Campos2 and Cesar Avila2

1Department of Social Psychology, University Jaume I, Spain

${ }_{2}$ Department of Basic Psychology, University Jaume I, Spain

\begin{abstract}
People are capable of understanding the suffering of distant others and of their personal responsibility in this suffering. The communication of harm and self-responsibility in the suffering of others leads to greater moral sensitivity. Two studies were carried out to test our hypotheses. In Study 1 we analyse the emotional response to the scripts using a correlational study. In Study 2 we use functional MRI to investigate brain activation associated with the communication of harm and self-responsibility in a moral scenario on supportive communication. Direct comparison between donor and protest scenarios yielded a significant activation in the left amygdala usually associated with moral emotions. Responses in supportive communication scenarios show that donors can feel personally involved in a moral issue if they perceive the harm and their selfresponsibility. Our results suggest that the creation of a communications structure based on social condemnation increases moral sensitivity to poverty.
\end{abstract}

\section{Keywords}

Protest scenario, Moral Sensitivity, Helping Groups, Supportive Communication, Neural Responses 
The role of self-responsibility

\section{INTRODUCTION}

The present paper seeks to shed light on the processing differences associated with moral sensitivity to helping social groups. To this end, we use the impersonal dilemma on whether to act to prevent the suffering of distant others and compare the emotional response, at subjective and neural levels. Relying on the communicative structure of a collective message, we compare two communication scenarios associated whith impersonal dilemmas: donor scenario and protest scenario.

Moral sensitivity represents a person's capacity to detect and interpret moral questions (Moll, Oliver-Souza, Garrido, Bramati, Caparelli-Daquer, Paiva, Zahn, \& Grafman, 2007). Moral psychology has recently studied the conditions in which people are sensitive to requests for help when moral rules are violated (Haidt, 2003; Greene, Sommerville, Nystrom, Darley, \& Cohen, 2001; Greene, 2003; Prinz, 2007). Moral dilemmas vary in the degree to which they engage emotional processing and this engagement influences moral judgment (Greene et al., 2001). These studies find that people feel emotionally involved in dilemmas of help in which the giver has a direct link with the recipient and denial of help causes physical harm to the person asking for help (Greene, Nystrom, Engell, Darley, \& Cohen, 2004; Greene, 2003). Emotional processing does not affect the neural response to moral dilemmas if there is no moral condemnation associated with the refusal of help. The absence of a direct personal link has been proposed as the main reason for this lack of emotional response (Greene, et al., 2001; \& Haidt, 2002). The perception of responsibility in the link with the recipient may have the same emotional effect as a direct physical relationship. In this study, we explore the conditions in which the communication of harm resulting from denial of 
The role of self-responsibility

help, may be a cognitive factor that engages emotional processing in an anonymous social context (scenario) where there is no direct link with the donor.

When a moral rule is judged to have been violated, the neural structures are activated to process a negative emotional response associated with the disapproval of this violation (Greene et al., 2001). This emotional activation varies according to whether the person thinks s/he has some direct responsibility for the violation of the moral norm (Greene et al., 2004). In moral scenarios in which the recipient of help is an anonymous, distant other, people find it difficult to judge as immoral the harm that denying help can cause, and to become emotionally involved (Greene et al., 2001; Greene \& Haidt, 2002). The communication strategies used by many of the large international NGOs tend to emphasize the role of the other's suffering, and draw attention to the need donate to an NGO to alleviate this suffering, exposing the recipient to a donor scenario (Benthall, 2010; CONCORD, 2007; Sogge, 1996). The absence of a direct, physical link with the recipient of help is typical of the donor scenario, and is therefore considered to be an impersonal moral dilemma, in which personal responsibility (self-responsibility) for the moral harm is indirect (Greene et al., 2001; Greene, 2003). The personal distance between the donor and the recipient is therefore physical, because of the nature of the dilemma, and psychological, because of the impersonal neural response reported by Greene et al. (2001).

The donation reaches the recipient the through an intermediary, who appears as directly responsible for the moral repair of the harm. The donor scenario places the donor in a situation in which s/he appears as responsible for the well-being of an anonymous person, but not directly responsible for the cause of the moral harm. In this context the request for help does not include any relevant information implicating the donor in the situation that is causing harm to the recipient. The collective nature of the request for 
The role of self-responsibility

help, therefore, might not be the only factor that inhibits the donor's emotional involvement. Attribution of self-responsibility for moral harm may be a relevant factor associated with the moral response. People can feel responsible for harm they have not inflicted themselves if they consider it has been perpetrated by someone from their own reference group, and they regard the harm caused as meriting condemnation (Branscombe, Doosje, \& McGarty, 2002; Branscombe, 2004; Wohl \& Branscombe, 2008). A variation of the donor scenario that cognitively links the donor with the recipient's suffering would therefore be expected to activate the neural response typical of personal moral dilemmas.

The concept of protest, however, emphasises the need to help impoverished countries by attributing direct responsibility for their precarious resources to the donors themselves. This differentiation contributes an aspect that is not covered in the differentiation between personal and impersonal moral dilemmas made by Greene et al. (2001, 2004): the direct responsibility for an action that merits condemnation as a link between the donor and the recipient. The protest scenario overcomes physical distance by bringing the donor and the recipient cognitively closer, thus enabling a more significant emotional response. This narrowing of the cognitive distance means, in practice, increased moral sensitivity to the situation, which can be seen in the correlatively activated neural structure In the donor scenario not helping can generate an unpleasant feeling of guilt, by performing an action that is not morally acceptable, the consequence of which is the other’s suffering (Greene, 2004; Baumeister, Stillwell \& Heatherton, 1994; Lazarus, 1991). Guilt is a self-conscious moral emotion, part of which is the thought of responsibility for harming the other (Lazarus, 1991); the person is aware of his or her responsibility in a moral transgression that harms others if he or she does not do the 
The role of self-responsibility

right thing (Lazarus, 1991, Baumeister et al., 2004). In the donor scenario, the person anticipates feeling guilty if he or she does not help the other. The appeal for help is thus managed as a problem to be resolved. The person approaches the question of whether to help or not as a problem of choosing between two options: a) not to give money and then feel guilty as a result; and b) to give money and then forget the problem. Guilt is anticipated, the person has to decide in order to prevent it, and as such the socioemotional circuit is key to the response. In the donor scenario, the person will be responsible for the harm caused if he or she does not act, by not helping someone in need, and by not taking responsibility for resolving the situation. By helping, he or she is no longer responsible for the situation facing the person requesting help, and can turn his or her back on and disengage from the problem that led to the appeal. In contrast to the donor scenario, the protest scenario provides a communication structure in which the audience can judge their own self-responsibility in the possibility of acting to resolve the problem, by pressurizing their reference group to prevent the conditions that lead to the problem. These judgments will be associated with aversive emotions of condemnation such as guilt or/and indignation over the harm caused. Emotions of condemnations like indignation are critical in the response to the breach of moral norms (Haidt, 2003). They arise when the moral codes affecting the community are violated. These emotions tend to lead to action by inducing pro-social responses such as helping others (Haidt, 2003; Moll, De Oliveira-Souza, Moll \& Ignacio, 2005); they form part of the state in which the person has to take his or her decision, which implies that the socio-emotional circuit is directly involved.

Robertson, Snarey, Ousley, Harenski, Bowman, Gilkey and Kilts (2007) have reported that sensitivity to moral issues correlates with the activation of the polar medial prefrontal cortex, dorsal posterior cingulate cortex, and posterior superior temporal 
The role of self-responsibility

sulcus (STS). Personal dilemmas generally involve regions of the brain associated with emotion; the amygdala is particularly important, but the mPFC (medial Pre-Frontal Cortex) and dorsal posterior cingulate cortex are also relevant (Greene et al., 2001; Greene et al., 2004). Impersonal dilemmas, on the other hand, involve regions such as the DLFPC (Dorso Lateral Fronto Parietal Cortex), which are linked to cognitive control (Greene, et al., 2001; Miller \& Cohen, 2001). Although the role of emotions in moral judgments is still unclear (Huebner, Dwyer, \& Hauser, 2008), the amygdala emerges as the principle brain structure carrying out an essential role in regulating social emotions, as well as emotions related to indignation over unjust acts (Adolphs, Tranel, \& Damasio, 1998; Adolphs, 2002, 2003). The amygdala could be a critical area in comparing the two supportive communication scenarios because of its particular and critical role in activating emotional responses to actions that physically harm others, and/or where intentional moral transgressions are present (Berthoz, Grezes, Armony, Passingham, \& Dolan, 2006; Luo, Nakic, Wheatley, Richell, Martin, \& Blair, 2006; Heekeren, Wartenburger, Schmidt, Prehn, Schwintowski, \& Villringer, 2005; Greene, 2009). Attribution of personal responsibility for the action of a social group may increase moral sensitivity to the situation, by allowing the socio-emotional response to modulate to the context (Moll et al., 2007; Zahn, Moll, Paiva, Garrido, Krueger, Huey, \& Grafman, 2009). One social group scenario that involves greater attribution of personal responsibility for harm to another person, associated with personal moral judgment, is the protest scenario. In this context, the denouncement of an unjust situation, together with attribution of self-responsibility as a member of the group causing the harm, would lead to a demand for protest as a way of condemning the situation. 
The role of self-responsibility

We hypothesise that aversive emotional response will be more intense in the protest scenario than in the donor scenario. This negative response will be manifest both at a self-reporting level (Study 1) and in the activation of brain areas associated with aversive processing such as the amygdala (Study 2). We hypothesise that activation of the amygdala will be more intense in the context of helping social groups in the protest scenario than in the donor scenario.

\section{Method.}

\section{Study 1}

\section{Participants}

247 undergraduates (173 females and 74 males; mean age $=22.30$; range 19-36) were studied, all of whom had given their prior informed consent. 115 undergraduates responded to the donor scenario scripts, 132 undergraduates responded to the protest scenario scripts.

\section{Scripts}

Twelve scripts (action scenarios) were prepared to evoke the experience of protest (6 protest scripts) and donation (6 donor scripts). The donor scripts were based on a preliminary analysis of advertising used by some large NGOs (e.g., Amnesty International, UNICEF, Intermon Oxfam). Public denouncements of transnational corporations' actions in their business activities (Werner \& Weiss, 2003) were used in the preparation of the protest scripts. All the scripts (see Table 1) began with a sentence to indicate their content: 'Thousands of people urgently need help to survive' for the donor scripts and 'It is unjust and outrageous' for the protest scripts. The content of these 12 scripts was evaluated by 23 experts (students and/or professionals from the area of cooperation) who were asked to decide which category the scripts belonged to, without being given any identifying labels. The experts reached a unanimous decision 
The role of self-responsibility

on 11 of the 12 scripts, classifying them in the category to which they had originally been assigned. Script A6 from the protest category was classified correctly by $91 \%$ of the expert panel.

(Table 1 about here)

The design of both the scenarios was based on the presentation of the donor dilemma in the study of Greene et al. (2001). In Greene et al.'s (2001) work, the structure of donor dilemma includes the presentation of the social problem and the demand for action. In our study, the scripts are structured similarly. We have designed them as a variation of the donor dilemma. In this variation, we have attempted to create a situation that more closely represents a social communication scenario. The study by Greene et al. (2001) does not employ social communication analysis, but rather presents the dilemma as a moral problem confronting the individual faced with the possibility to help anonymous beings with whom he/she has no physical contact (impersonal dilemmas). By presenting this dilemma as a communication scenario, the very dilemma and action are linked dialectically, suggesting that associating the protest dilemma with a demand for monetary action would, in the communicative structure, result negatively and be of little credibility, thereby adversely affecting the public's response. Other message or contextualisation formulas may have different effects, although we used this formula to differentiate the context of personal responsibility (protest dilemma) from one of psychological distance from the problem (donor dilemma). Each scenario was differentiated by an opening phrase that contextualised the scenario in which the donor had to act. The test to evaluate recognition of the differences between the two scenario types verified that the subjects clearly saw the differences between the two contexts

\section{Procedure}


The role of self-responsibility

Each of the 12 scripts was presented separately to groups of between 17 and 24 participants such that each participant only evaluated one script. Written scripts were given to the participants to read, and they were then asked to evaluate their emotional state on a scale of 1 to 7 , based on a list of five positive and five negative adjectives. The emotional state has been assessed from a list of potential emotions that could be triggered by the scripts. A first group of negative emotions (ashamed, guilty, disgusted, angry and indignant), because individuals respond emotionally with aversion or rejection towards the object or situation that triggers its appearance. A second group of positive emotions (cheerful, encouraged, compassionate, hopeful, y happy). They were also asked to assess the degree of morality of the script by evaluating, on a scale of 1 to 7 , the following statement: ' $I$ think it is immoral to do nothing to prevent this situation'. The questionnaire was given to the students in class, following an explanation and request for permission from the students and their lecturers.

\section{Results and Discussion}

The results of the emotional evaluations enabled us to calculate the positive and negative affect scores for responses to each scenario. We carried out an exploratory factor analysis using the principal components and varimax rotation procedures. This analysis resulted in a two-factor solution with an eigenvalue above 1 , coinciding with the positive and negative emotions. The explained variance of the factor solution is 61.474\%. The factor loading for the positive emotions factor oscillated between .566 and .891, while that for the negative emotions factor was between .582 and .873 . Cronbach’s alpha for the negative emotions factor was .807 and for the positive emotions, .777. A 2x2 ANOVA was performed using affect type (positive vs. negative) as the within-subjects factor and scenario (protest vs. donor) as the between-subjects factor. As expected, in the scenario factor in relation to positive affect $(\mathrm{F}=4.559 *)$, the 
The role of self-responsibility

donor scenario $(\mathrm{M}=2.113$; d.t. =1.056) presented greater positive affect than protest scenario $(\mathrm{M}=1.854$; d.t. $=.824)$, and the analysis of the negative affect revealed significant differences $\left(\mathrm{F}=10.135^{* *}\right)$ : the protest scenario presented greater negative affect $(M=4.383$; d.t. =1.288) than the donor scenario $(\mathrm{M}=3.856$; d.t. =1.249).

The results of the differences for each item are presented in Table 2. On analyzing the adjectives, the evaluation of the protest group was more negative than the donor group for four of the five negative adjectives: disgust, anger, shame and indignation. In general there were no differences between the two scenario types with regard to the positive emotional states. Only in the case of the adjective 'hope' was a lower score obtained in the protest than in the donor scenario (see Table 2).

(Table 2 about here)

Significant differences were, however, found in the scenario factor $(F=5.533 ; \mathrm{p}<.05)$ regarding the evaluation of the morality of refusing help; the protest scenario revealed a higher perception of immorality for denying help in the script $(\mathrm{M}=5.832$; d.t.=1.376) than the donor scenario ( $\mathrm{M}=5.409$; d.t. $=1.444)$.

The second study was designed to compare the two scenarios at the level of brain response.

\section{Study 2}

\section{Participants}

Eighteen undergraduates (8 females; mean age $=21.90$; range 19-31) were studied, all of whom had given their written informed consent. The experiment was approved by the Ethics Committee of the University Jaume I. All subjects were right-handed according to the Edinburgh Handedness Inventory (Oldfield, 1971), and did not report any neurological and psychiatric disorders.

\section{fMRI paradigm}


The role of self-responsibility

Participants were required to watch an 8-minute film and to remember the auditory sentences generated with the software Text Aloud (V. 2.7), using the 'George’ voice. This software guarantees that the same voice, with no prosodic tone, is heard during the entire task. Using selected fragments from documentaries, we constructed a single videotape consisting of 18 contiguous 20 -second segments alternating three different conditions: the Protest condition, the Donor condition and the control condition. Both Protest and Donor conditions presented videos showing explicit images of poverty in the Third World. Two sets of videos were selected and these were counterbalanced across subjects. The same messages from Study 1 (see Table 1) were presented within each condition according to whether they were Protest or Donor. All the scripts (see Supplementary Information) began with a sentence to indicate their content: 'Thousands of people urgently need help to survive' for the donor scripts and 'It is unjust and outrageous' for the protest scripts. Communication of the different help context was thereby guaranteed in each scenario type. Finally, the control condition showed black screens for 20-second periods.

A post scan test was used to evaluate attention during the scanning session by a recognition test of eighteen written sentences in which the messages heard in the scanner were either included or omitted. Sentences were randomly ordered for each subject. Twelve of these sentences corresponded to the scripts from the study. Six other phrases with content unrelated to the study, were interspersed among the scripts. The test asked subjects to answer "yes" or "no" if they had previously heard these sentences during the scanner session.

\section{fMRI Acquisition}

Blood oxygenation level dependent (BOLD) fMRI data were acquired on a 1.5T Siemens Avanto (Erlangen, Germany). Subjects were placed in the MRI scanner in a 
The role of self-responsibility

supine position. Their heads were immobilised with cushions to reduce motion artifact. The stimuli were directly presented using Visuastim XGA goggles with a resolution of 800 x 600 (Resonance Technologies, Inc). Vision correction was used whenever necessary.

A gradient-echo T2*-weighted echo-planar MR sequence was used for fMRI in both tasks $\left(\mathrm{TE}=50 \mathrm{~ms}, \mathrm{TR}=3000 \mathrm{~ms}\right.$, flip angle $=90^{\circ}$, matrix $=64 \mathrm{x} 64$, voxel size $=3.94 \mathrm{x}$ 3.94 x 6, with $5 \mathrm{~mm}$ thickness and $1 \mathrm{~mm}$ gap). We acquired 29 interleaved axial slices parallel to the anterior-posterior commissure (AC-PC) plane covering the entire brain. Prior to the functional MR sequence, an anatomical 3D volume was acquired using a T1-weighted gradient echo pulse sequence $(\mathrm{TE}=4.9 \mathrm{~ms} ; \mathrm{TR}=11 \mathrm{~ms} ; \mathrm{FOV}=24 \mathrm{~cm}$; matrix= $256 \times 224 \times 166$; voxel size= $1 \times 1 \times 1$ ).

\section{fMRI data analysis}

The data were analysed using Statistical Parametric Mapping (SPM5). For each subject, the first two scans in each run were excluded from the analysis to discount artifacts related to the transient phase of magnetisation. Motion correction to the first functional scan was performed with subjects using a six-parameter rigid-body transformation. All the individuals' anatomical images were co-registered to the mean of their functional images using a rigid-body transformation. Images were then spatially normalised to the Montreal Neurological Institute (MNI) template conforming to the Talairach orientation system by applying a 12-parameter affine transformation followed by nonlinear warping using basis functions. The computed transformation parameters were applied to all the functional images, interpolating to a final voxel size of $3 \times 3 \times 3 \mathrm{~mm}^{3}$. Subsequently, images were spatially smoothed with a $6 \mathrm{~mm}$ isotropic Gaussian kernel.

A two-stage procedure was used for the statistical analysis. At the first level (fixed effects), the fMRI data from each individual participant were used to generate statistical 
The role of self-responsibility

contrast images after comparing brain activation between each experimental condition and the control condition (Protest $>$ Control Condition; Donor $>$ Control Condition). The whole brain voxelwise analysis of main task-related effects was studied using a statistical threshold of $\mathrm{p}<0.05$ FWE corrected for multiple comparison, and an extent threshold of $216 \mathrm{~mm}^{3}$ across the whole brain.

To test our hypothesised higher activation in the amygdala for the Protest condition than the Donor condition, the region-of interest (ROI) analysis with small volume (SV) correction (Worsley, Marrett, Neelin, Vandal, Friston, Evans, 1996) was carried out for the direct contrast of Protest $>$ Donor conditions. The amygdalas were defined bilaterally as a ROI with the Anatomical Automatic Labeling (AAL) atlas (Tzourio-Mazoyer, Landeau, Papathanassiou, Crivello, Etard, Delcroix, Mazoyer \& Joliot, 2002) as implemented in the WFU PickAtlas toolbox (Maldjian, Laurienti, Kraf, Burdette, 2003) for SPM5. Statistical significance of brain activation within our ROI was defined unilaterally at $\mathrm{p}<0.05$, FWE small volume correction. Furthermore, we conducted a whole brain voxelwise analysis to test for any other functional differences between these two conditions (Protest vs. Donor), at the same statistical thresholds applied to study task-related activations $\left(\mathrm{p}<0.005\right.$, uncorrected; extent threshold $=216 \mathrm{~mm}^{3}$ )

\section{Results}

All participants correctly identified more than $89 \%$ of the sentences in the post-scan test. As expected, viewing the experimental videos produced strong brain activations in the occipital, temporal and parietal areas, as well as the thalamus (see Table 3; Figure 1).

(Table 3 about here)

(Figure 1 about here) 
The role of self-responsibility

Also in line with expectations, the Protest> Donor comparison yielded a significant activation in the left amygdala $(x, y, z$ MNI coordinates $=-27,-4,-12 ; z=3.20, p<0.05$ FWE small volume correction). In an additional whole brain voxelwise analysis, we found significant activations in limbic and temporal areas including the parahippocampal gyrus and the middle temporal lobe $(\mathrm{p}<0.005$, uncorrected; Table 4). Likewise, the reverse contrast (Donor>Protest) activated cortical and cingulate areas (see Table 5). Contrast activations for the whole brain direct voxelwise comparisons between Protest and Donor conditions appear in Figure 2.

(Table 4 and 5 about here)

(Figure 2 about here)

\section{Discussion}

The study was designed to compare emotional response to two variations of the supportive communication scenario. We aimed to shed light on the differences in neural processing related to moral sensitivity to helping groups, associated with contextual differences. The classic scenario used to analyse moral response to the request for help for social groups emphasises the request for money to alleviate precarious economic situations. The question that the study attempted to clarify is twofold: firstly, to explore the question of whether the communicative strategy based on the donor scenario sensitises its audience in a moral way; and secondly, whether alternative communication strategies can be proposed that have a greater potential for developing moral sensitivity.

We hypothesised that aversive emotional response would be more intense in the personal responsibility scenario than in the scenario with no responsibility, due to the moral condemnation of a situation in which a conduct causes harm to another. Our results show that this negative response is manifest both at the self-report level (Study 
The role of self-responsibility

1) and in the activation of brain areas associated with aversive socio-emotional processing like the amygdala (Study 2). Coinciding with studies on moral sensitivity and donor behaviour, (Greene et al. 2001) our results suggest that communication strategies based on the donor scenario activate a more emotionally disengaged decision mechanism. This response is in line with the view of poverty as a rational problem to be solved, involving little empathy or moral comprehension of the harm caused to the other. The communication strategy based on the protest scenario, however, appears as a motivator of the decision-making process in which the socio-emotional circuit has a greater presence. This presence of the socio-emotional circuits reveals that the person feels more emotionally involved as a result of the harm he or she perceives the other to suffer.

In Study 1, the protest condition involves a greater degree of aversive emotional response, particularly moral condemnation such as anger, disgust or indignation. These emotions are generated in response to communication of a violation of moral norms, although indignation appears to be more closely linked to socio-emotional circuits (Haidt, 2003; Moll, Oliveira-Souza, Moll, Ignacio, Bramatic, Caparelli-Dáquer, Egas, \& Eslinger, 2005). In the protest condition, rejection of the situation of poverty generates a negative emotional response. These findings suggest that the donor is more involved in the recipient's problem when s/he considers the situation merits condemnation and takes responsibility for its cause. This emotional involvement may be due to a sense of individual responsibility for group motives; the donor, as a member of the reference group that has caused the harm, perceives herself as an agent of that harm (Branscombe, Doosje, \& McGarty, 2002).

The design of both the scenarios was based on the presentation of the donor dilemma in the study of Greene et al. (2001). In Greene et al.'s (2001) work the structure of donor 
The role of self-responsibility

dilemma includes the presentation of the social problem and the demand for action. In our study, the scripts are structured similarly. We have designed them as a variation of the donor dilemma. In this variation, we have attempted to create a situation that more closely represents a social communication scenario. The study by Greene et al. (2001) does not employ social communication analysis, but rather presents the dilemma as a moral problem confronting the individual faced with the possibility to help anonymous beings with whom he/she has no physical contact (impersonal dilemmas). By presenting this dilemma as a communication scenario, the very dilemma and action are linked dialectically, suggesting that associating the protest dilemma with a demand for monetary action would, in the communicative structure, result negatively and be of little credibility, thereby adversely affecting the public’s response. Other message or contextualisation formulas may have different effects, although we used this formula to differentiate the context of personal responsibility (protest dilemma) from one of psychological distance from the problem (donor dilemma).

The study's results introduce a new element in the understanding of how the violation of moral norms can give rise to moral emotions: the communication of personal responsibility for harm to another person with whom there is no physical connection. The protest scenario 'personalises' the problem of the group to a greater degree, and brings it closer to the donor. We therefore consider that these results contribute further evidence of the role of supportive communication in raising moral sensitivity to social group problems. The results allow for an interpretation that a moral question may be more moral if there is condemnation of the situation and responsibility for having caused it. Our findings appear to suggest the existence of a societal link between moral norms communication and emotional activation. 
The role of self-responsibility

The two scenarios analyzed in this paper vary in their emphasis in one or other aspect when they appeal for a response from the recipient. The donor scenario focuses on suffering caused by poverty, while the protest scenario highlights the social condemnation of the injustice of poverty. In both scenarios (donor and protest) the moral problem is the same: prevention of group suffering among distant, anonymous others resulting from a lack of economic resources. The variation in the direct communication of harm and self-responsibility changes the neural response.

This neural behaviour suggests that the moral emotion follows a prior judgement of the situation. The observer rejects the situation that has caused the other's suffering when she sees herself as an agent of that suffering, and similar emotions surface as those that would emerge if she were suffering injustice herself (anger, disgust, indignation). But perhaps this perceptive effect loses moral interest with habit. Future research should examine in greater depth the knowledge of how awareness of shared responsibility and/or blame can help to understand moral behaviour in help for groups in accordance with emotional response. When we have to help someone physically near us, the result of our help can be seen the moment we act. However, in social group problems, no direct positive reinforcement is obtained for the help offered, and the repeated experience of donating is often accompanied by the perception that the donation does not fulfil the purpose for which it was made. Perhaps the absence of a direct relationship with the outcome of the help given could be affecting the neural response and the moral judgement of the situation, and not the direct link with the donor in itself. The protest scenario may trigger a more significant emotional response perhaps because there is no repeated experience that leads to the perception that the help given is not providing results. The importance of the outcome in moral help may affect the moral judgement 
The role of self-responsibility

and the associated moral response; future research should explore in greater detail the importance of this factor in both individual and group moral scenarios.

\section{Practical Implications}

Our results suggest that the creation of a communication structure based on social condemnation, which activates indignation about the conditions of poverty, increases moral sensitivity to poverty. We suggest that future research might take up the analysis of the efficiency of moral sensitivity (once civil society individuals feel motivated to act) by communicating proposals, alternatives and possibilities to act to transform the perceived injustices. We feel more directly or personally involved if we acknowledge that we are the cause of, or responsible for, the situation. Therefore, a communication structure that frames the need to help in eradicating poverty and places responsibility on the donor can raise moral sensitivity to poverty. This communication strategy involves making the donor participate in the problem, without blaming him or her for it, which would encourage support for using more personalised education and communication strategies in collective messages. Finally, these results suggest the need for more participative forms of communication in which mutual recognition of the reasons for poverty form part of the debate. In summary, communication structures should allow the donor and the recipient to be active agents in their decisions, and open up reciprocal debate on their mutual dependencies..

\section{Limitations of the study}

In the donor scenario, moral violation occurs when allusions are made to the harm the recipient suffers if no donation is given. In the protest scenario, moral violation is evidenced through condemnation of the source of the suffering. The donor's responsibility is more explicit in the protest scenario. However, the neural response may be due to the initial condemnation of the moral situation in the protest scenario. 
The role of self-responsibility

Although we believe that this condemnation and the attribution of self-responsibility must go together to activate moral sensitisation, the study design does not allow us to clearly identify the specific role in moral judgements that attribution of selfresponsibility would have without prior condemnation of the situation. Furthermore, the absence of condemnation in the message would assume that there was no real differentiation in the donor's social context. The donor is therefore faced with a context that can generate two differentiated conditions. Other message or contextualisation formulas may have different effects, although we used this formula to differentiate the context of personal responsibility (protest scenario) from one of psychological distance from the problem (donor scenario).

\section{References}

Adolphs, R. (2002). Trust in the brain. Nature Neuroscience, 5, 192-193.

Adolphs, R. (2003). Cognitive neuroscience of human social behaviour. Nature Reviews Neuroscience, 4, 165-178.

Adolphs, R., Tranel, D., \& Damasio, A.R. (1998). The human amygdala in social judgment. Nature, 393, 470-474.

Benthall, J. (2010). Disasters, relief and the media. Reprinted with a new Preface, Wantage: Sean Kingston Publishing. First Edition.

Berthoz S., Grezes J., Armony J.L., Passingham R.E., \& Dolan, R.J. (2006). Affective response to one’s own moral violations. Neuroimage 31, 945-950.

Branscombe, N.R. (2004). A social psychological process perspective on collective guilt. In N.R. Branscombe, \& B. Doosje (Eds.), Collective guilt: International perspectives (pp. 320-334). New York: Cambridge University Press. 
The role of self-responsibility

Branscombe, N.R., Doosje, B., \& McGarty, C. (2002). Antecedents and consequences of collective guilt. In D.M. Mackie, \& E.R. Smith (Eds.), From prejudice to intergroup emotions (pp. 153-171). New York: Psychology Press.

CONCORD (2007). Code of conduct on images and messages. http://www.deeep.org/codeofconduct.html.

Damasio, A. (1994). Descartes' error: Emotion, reason and the human brain. New York: GP Putnam’s Sons.

General Assembly of European NGOs (1989). Code of conduct on Messages and Images.

Grodijn, E.H., Wigboldus, D., \& Yzerbyt, V. (2001). Emotional consequences of categorizing victims of negative outgroup behavior as ingroup and outgroup. Group Processes and Intergroup Relations, 4, 317-326.

Greene, J.D. \& Haidt, J. (2002). How (and were) does moral judgment work?. TRENDS in Cognitive Science, 6(12), 517-523.

Greene, J. D. (2003). From neural 'is' to moral 'ought': what are the moral implications of neuroscientific moral psychology? Nature Reviews Neuroscience 4, 846-849.

Greene, J.D., Nystrom, L.E., Engell, A.D., Darley, J.M., \& Cohen, J.D. (2004). The neural bases of cognitive conflict and control in moral judgment. Neuron, 44, 389-400. Greene, J.D. (2009). The cognitive neuroscience of moral judgment. In M.S. Gazzaniga (Ed), The Cognitive Neurosciences IV. Cambridge: MIT Press.

Greene, J.D., Sommerville, R.B., Nystrom, L.E., Darley, J.M., \& Cohen, J.D. (2001). An fMRI investigation of emotional engagement in moral judgment. Science 293, 2105-2108.

Haidt, J. (2003). The moral emotions. In Davidson R.J., Scherer K., \& Goldsmith H. (Eds). Handbook of Affective Sciences (pp. 852-870). Oxford: Oxford University Press. 
The role of self-responsibility

Heekeren H.R., Wartenburger I., Schmidt H., Prehn K., Schwintowski H.P., \& Villringer, A. (2005). Influence of bodily harm on neural correlates of semantic and moral decision-making. Neuroimage, 24, 887-897.

Huebner, B., Dwyer, S. \& Hauser, M. (2008). The role of emotion in moral psychology. TRENDS in Cognitive Sciences, 13, 1-6.

Lazarus, R.S. \& Lazarus, B.N. (1994). Passion \& Reason. Oxford University Press: New York.

Luo, Q., Nakic, M., Wheatley, T., Richell, R., Martin, A., \& Blair, R.J. (2006). The neural basis of implicit moral attitude-An IAT study using event-related fMRI. Neuroimage, 30, 1449-1457.

Maldjian, J.A., Laurienti, P.J., Kraf, R.A., Burdette, J.B. (2003). An automated method for neuro-anatomic and cytoarchitectonic atlas-based interrogation of fMRI data sets. NeuroImage 19, 1233-1239.

Miller, E.K, \& Cohen, J.D. (2001). An integrative theory of prefrontal cortex function. Annual Rev Neurosci, 24,167-202.

Moll, J., de Oliveria-Souza, R., Moll, F.T., Ignacio, F.A., Bramati, I.E., CaparelliDáquer, E.M., \& Eslinger, P.J. (2005). The moral affiliations of disgust: a fMRI study. Cognitive Behavioral Neurology, 18 (1), 68-78.

Moll, J., Zahn, R., de Oliveira-Souza, R., Krueger, F., \& Grafman, J. (2005). Opinion: the neural basis of human moral cognition. Nature Reviews: Neuroscience, 6, 799-809. Moll, J.; de Oliveira-Souza, R.; Garrido, G.J.; Bramati, I.E.; Caparelli-Daquer, E.M.A.; Paiva, M.L.M.F., Zahn, R. \& Grafman, J. (2007). The self as a moral agent: Link-ling the neural bases of social agency and moral sensitivity. Social Neuroscience, 3-4 (2), 336-352. 
The role of self-responsibility

Narvaez, D., \& Rest, J. (1995). The four components of moral behavior. In W. Kurtines, \& J. Gewirtz (Eds.), Moral behavior and moral development: An introduction (pp. 385399). New York, NY: McGraw-Hill.

Oldfield, R. C. (1971). The assessment and analysis of handedness: The Edinburgh inventory. Neuropsychologia, 9,(1), 97-113.

Prinz, J.J. (2007). The emotional constructions of morals. Oxford University Press Robertson D., Snarey J., Ousley O., Harenski K., DuBois Bowman F., Gilkey R, \& Kilts C. (2007). The neural processing of moral sensitivity to issues of justice and care. Neuropsychologia, 45, 755-766.

Sogge, D. (1996). Compassion \& calculation. The business of private foreign aid, London: Pluto Press/Transantional Institute.

Tzourio-Mazoyer, N., Landeau, B., Papathanassiou, D., Crivello, F., Etard, O., Delcroix, N., Mazoyer B, \& Joliot M. (2002). Automated anatomical labelling of activations in spm using a macroscopic anatomical parcellation of the MNI MRI single subject brain. Neuroimage, 15, 273-289.

Weiner, B. (1995). Judgments of responsibility: A foundation for a theory of social conduct. New York: Guilford.

Werner, K., \& Weiss, H. (2003). Das neue schwarzbuch markenfirmen. Die machenschaften der weltkonzerne. Viena-Frankfurt del Main: Franz Deuticke Publishing Company.

Wohl, M. J. A., \& Branscombe, N. R. (2008). Remembering historical victimization: Collective guilt for current ingroup transgressions. Journal of Personality and Social Psychology, 94, 988-1006.

Worsley, K.J., Marrett, S., Neelin, P., Vandal, A.C., Friston, K.J., Evans, A.C. (1996). A unified statistical approach for determining significant voxels in images of cerebral activation. Human Brain Mapping 4, 58-73. 
The role of self-responsibility

Zahn, R., Moll, J., Paiva1, M., Garrido, G., Krueger, F., Huey, E. D., \& Grafman, J. (2009). The neural basis of human social values: Evidence from fMRI. Cerebral Cortex, 19 (2), 276-283. 
The role of self-responsibility

Table 1

Translated scripts and frequency of response to each script in the behavioural study

Donor Group

Message

$\mathbf{N}$

D1. Thousands of people urgently need help to survive. They do not have enough food or water, or any way of getting them for themselves. They are victims of war in their countries. With your help we can save women and children, victims of armed conflicts, from hunger. Make a donation to our NGO!

D2. Thousands of people urgently need help to survive. With your help we can halve the number of people living on less than one euro a day. Help us to get rid of extreme poverty and hunger. Make a donation to our NGO!

D3. Thousands of people urgently need help to survive. Just $€ 12$ a month can provide 125 vaccinations against measles, an illness that causes infant deaths in countries with no resources. This is only one example of how you can help us to help them. Make a donation to our NGO!

D4. Thousands of people urgently need help to survive. With your help, the number of children registered in primary schools in the developing regions where we have been active has increased by $80 \%$. Our target is to 18 achieve universal primary education. Make a donation to our NGO! 
The role of self-responsibility

D5. Thousands of people urgently need help to survive. Official calculations show that 10 million African children die every year from causes that can be prevented before they reach their fifth birthday. With your help, we can give them the medicines they need. Make a donation to our NGO!

D6. Thousands of people urgently need help to survive. With your help, we can provide the medical assistance they need. With $€ 10$ a year, we can send a full surgical team to a country at war or we can vaccinate 400 children against meningitis. Make a donation to our NGO! TOTAL

Protest Group

Message

P1. It is unjust and outrageous. Our companies employ children in Laos to manufacture cheap training shoes. These children have to work for paltry wages in order to eat. Just 36 cents more would enable them to go to school and stop working. And we say nothing. Break that silence. Protest!

P2. It is unjust and outrageous. African children are working for our Western companies, picking cocoa beans to make chocolate. Our companies treat them like slaves; they pay them nothing, so we can buy their products at a cheap price. And we say nothing. Break that silence. Protest! 
The role of self-responsibility

P3. It is unjust and outrageous. The mineral resources in African

countries belong to our Western companies. Instead of using them to create employment and wealth in the country, our companies hire armies

to guarantee their slave labour and cheap prices. And we say nothing.

Break that silence. Protest!

P4. It is unjust and outrageous. Our companies pay women workers in

China one euro for a 15-hour shift. They cannot take a day off, and they have no social security. These women pay for their food and to sleep in the factory. Break the silence. Protest!

P5. It is unjust and outrageous. The multinational oil companies hire armies and bribe governments so they can destroy the livelihood of millions of people living on the lands they want to exploit. And we say nothing. Break that silence. Protest!

P6. It is unjust and outrageous. Sports equipment companies spend their money on advertising and design. They keep thousands of workers in subhuman conditions, but they are not prepared to spend one cent to provide decent working conditions in their production plants. Break the silence, protest!

TOTAL 
The role of self-responsibility

Table 2

ANOVA of agency and donor scenarios, according to emotions

\begin{tabular}{|c|c|c|c|}
\hline Positive emotions & Donor & Protest & $F$ \\
\hline cheerful & $\begin{array}{l}1.82 \\
(1.15)\end{array}$ & $\begin{array}{l}1.58 \\
(.98)\end{array}$ & 3.07 \\
\hline encouraged & $\begin{array}{l}2.05 \\
(1.27)\end{array}$ & $\begin{array}{l}1.82 \\
(1.03)\end{array}$ & 2.44 \\
\hline hopeful & $\begin{array}{l}2.81 \\
(1.60)\end{array}$ & $\begin{array}{l}2.38 \\
(1.44)\end{array}$ & $4.86^{*}$ \\
\hline happy & $\begin{array}{l}1.72 \\
(1.17)\end{array}$ & $\begin{array}{l}1.63 \\
(.98)\end{array}$ & 0.47 \\
\hline TOTAL & $\begin{array}{l}2.61 \\
(0.86)\end{array}$ & $\begin{array}{l}2.44 \\
(.71)\end{array}$ & 2.69 \\
\hline Negative emotions & Donor & Protest & $F$ \\
\hline ashamed & $\begin{array}{l}3.94 \\
(1.88)\end{array}$ & $\begin{array}{l}4.82 \\
(1.71)\end{array}$ & $14.49 * * *$ \\
\hline guilty & $\begin{array}{l}3.03 \\
(1.56)\end{array}$ & $\begin{array}{l}2.88 \\
1.54)\end{array}$ & 0.62 \\
\hline disgusted & $\begin{array}{l}4.38 \\
(1.71)\end{array}$ & $\begin{array}{l}4.92 \\
(1.68)\end{array}$ & $6.22 *$ \\
\hline angry & $\begin{array}{l}3.48 \\
(1.78)\end{array}$ & $\begin{array}{l}4.19 \\
(1.73)\end{array}$ & $9.93 * *$ \\
\hline indignant & $\begin{array}{l}4.26 \\
(1.76)\end{array}$ & $\begin{array}{l}5.06 \\
(1.59)\end{array}$ & $13.70 * * *$ \\
\hline TOTAL & 3.86 & 4.38 & $10.13^{* *}$ \\
\hline
\end{tabular}


The role of self-responsibility

(1.24) (1.29)

${ }^{*} \mathrm{p}<.05 * * \mathrm{p}<.001 * * * \mathrm{p}<.0001$ 
The role of self-responsibility

Table 3

Task-related local maxima for each cluster of significant activation in Protest and Donor compared to the control condition ( $\mathrm{p}<0.05$; FWE corrected, cluster extent threshold of $\left.216 \mathrm{~mm}^{3}\right)$.

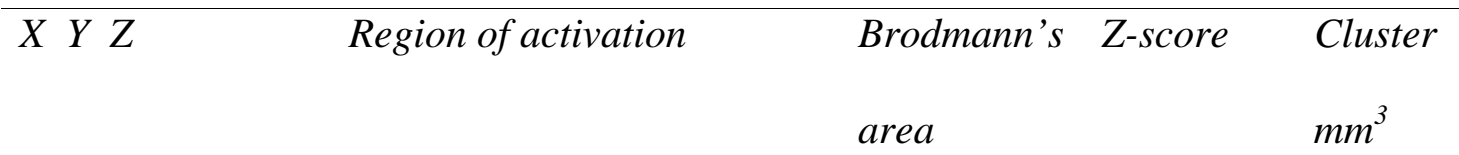

\section{Protest $>$ Control Condition}

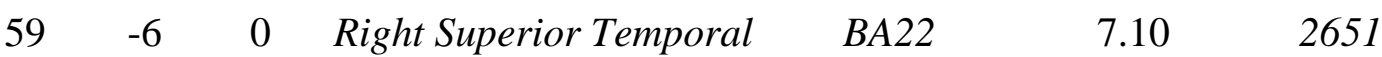

Gyrus

$\begin{array}{llllll}59 & -17 & 1 & \text { Right Superior Temporal } & \text { BA22 }\end{array}$

Gyrus

$\begin{array}{llll}62 & -20 & 12 & \text { Right Superior Temporal }\end{array}$

Gyrus

$9 \quad-70 \quad-2 \quad$ Right Lingual Gyru

BA18

7.08

23976

$\begin{array}{llll}-48 & -70 & 1 & \text { Left Inferior Temporal }\end{array}$

6.56

Gyrus

$12 \quad-86 \quad 21 \quad$ Right Cuneus

BA18

6.53

$\begin{array}{llll}-59 & -17 & 1 & \text { Left Superior Temporal }\end{array}$

BA22

6.16

2997

Gyrus

$\begin{array}{llll}-50 & -20 & 1 & \text { Left Superior Temporal }\end{array}$

Gyrus

$\begin{array}{llll}-59 & -29 & 7 & \text { Left Superior Temporal }\end{array}$

BA42

5.43

Gyrus

\section{Donor $>$ Control Condition}


The role of self-responsibility

\begin{tabular}{|c|c|c|c|c|c|c|}
\hline 9 & -87 & 18 & Right Cuneus & BA 18 & 7.00 & 31185 \\
\hline 9 & -70 & -2 & Right Lingual Gyrus & BA 18 & 6.46 & \\
\hline 12 & -86 & 21 & Right Cuneus & BA 18 & 6.08 & \\
\hline-33 & -84 & 10 & Left Middle Occipital Gyrus & BA 19 & 6.73 & \\
\hline 53 & -20 & 7 & $\begin{array}{l}\text { Right Superior Temporal } \\
\text { Gyrus }\end{array}$ & BA 41 & 5.92 & 5886 \\
\hline 65 & -17 & 4 & $\begin{array}{l}\text { Right Superior Temporal } \\
\text { Gyrus }\end{array}$ & BA 22 & 5.29 & \\
\hline 62 & -6 & 0 & $\begin{array}{l}\text { Right Superior Temporal } \\
\text { Gyrus }\end{array}$ & & 6.47 & \\
\hline-65 & -14 & 6 & $\begin{array}{l}\text { Left Superior Temporal } \\
\text { Gyrus }\end{array}$ & BA 42 & 6.26 & 2511 \\
\hline-50 & -31 & 13 & $\begin{array}{l}\text { Left Superior Temporal } \\
\text { Gyrus }\end{array}$ & BA 41 & 5.60 & \\
\hline-62 & -6 & 3 & $\begin{array}{l}\text { Left Superior Temporal } \\
\text { Gyrus }\end{array}$ & BA 22 & 6.38 & \\
\hline-21 & -64 & -4 & Left Lingual Gyrus & BA 19 & 6.17 & 513 \\
\hline-27 & -56 & -5 & $\begin{array}{l}\text { Left Parahippocampal } \\
\text { Gyrus }\end{array}$ & BA 19 & 6.11 & \\
\hline 18 & -26 & 1 & Right Thalamus & & 5.57 & 405 \\
\hline
\end{tabular}


The role of self-responsibility

Table 4

Local maxima for each cluster of significantly higher activation in Protest than in Donor $\left(\mathrm{p}<0.005\right.$; uncorrected, cluster extent threshold of $216 \mathrm{~mm}^{3}$ ).

\begin{tabular}{|c|c|c|c|c|c|c|}
\hline \multicolumn{3}{|c|}{$X Y Z$} & \multirow[t]{2}{*}{ Region of activation } & Brodmann & Z Score & Cluster \\
\hline & & & & \multicolumn{2}{|l|}{ 's area } & $m m^{3}$ \\
\hline-18 & -93 & 13 & Left Occipital Lobe/Cuneus & $B A 18$ & 3.95 & 540 \\
\hline 48 & -58 & 8 & Right Middle Temporal Gyrus & BA 39 & 3.90 & 1377 \\
\hline 24 & -21 & -9 & Right Parahippocampal Gyrus & BA28 & 3.87 & 432 \\
\hline \multirow[t]{2}{*}{-30} & -35 & -6 & Left Parahippocampal Gyrus & & 3.44 & 216 \\
\hline & & & \multicolumn{2}{|l|}{ Hippocampus } & & \\
\hline-30 & -36 & -13 & \multicolumn{2}{|l|}{ Left Fusiform Gyrus } & 2.69 & \\
\hline 62 & -4 & -17 & Right Inferior Temporal Gyrus & BA 21 & 3.31 & 621 \\
\hline \multirow[t]{2}{*}{-27} & -4 & -12 & \multicolumn{2}{|l|}{ Left Parahippocampal Gyrus } & 3.20 & 216 \\
\hline & & & \multicolumn{2}{|l|}{ Amygdala } & & \\
\hline \multirow[t]{2}{*}{-48} & 7 & -31 & Temporal Lobe & BA 21 & 3.19 & 513 \\
\hline & & & \multicolumn{2}{|l|}{ Temporal Gyrus } & & \\
\hline
\end{tabular}


The role of self-responsibility

\section{Table 5}

Local maxima for each cluster of significantly higher activation in Donor than in Protest $\left(\mathrm{p}<0.005\right.$; uncorrected, cluster extent threshold of $\left.216 \mathrm{~mm}^{3}\right)$.

\begin{tabular}{lllllll}
\hline$X$ & $Y$ & $Z$ & Region of activation & Brodmann's & Z Score & Cluster \\
& \multicolumn{7}{c}{ area } & & $\mathrm{mm}^{3}$ \\
\hline 6 & -80 & 37 & Right Cuneus & BA 19 & 4.08 & 2430 \\
-18 & -60 & 31 & Left Precuneus & BA 7 & 3.77 & \\
-6 & -80 & 40 & Left Precuneus & BA 19 & 2.81 & \\
3 & -31 & 24 & Right Posterior Cingulate & BA 23 & 3.21 & 648 \\
-3 & -25 & 29 & Left Cingulate Gyrus & BA 23 & 3.04 & \\
3 & 22 & 35 & Right Cingulate Gyrus & BA 32 & 3.13 & 459 \\
12 & -65 & 47 & Right Precuneus & BA 7 & 2.84 & 297 \\
12 & -65 & 39 & Right Precuneus & BA 7 & 2.66 & \\
\hline
\end{tabular}


The role of self-responsibility

\section{Figure 1}

Activation maps overlaid on an anatomical glass brain image for the Protest and Donor conditions ( $<<0.05$; FWE corrected).

Footnote: Colour bar represents contrast value on an intensity scale. Left is left. 
The role of self-responsibility

\section{Figure 2}

Contrast-map activation overlaid on an anatomical glass brain image for the comparison between a) Protest condition higher than Donor condition (axial slice shows detailed brain activation at amygdala for the whole brain analysis) and b) Donor condition higher than Protest condition.

Footnote: Colour bar represents contrast value on an intensity scale. Left is left. 